University of Nebraska - Lincoln

DigitalCommons@University of Nebraska - Lincoln

To Improve the Academy

Professional and Organizational Development

Network in Higher Education

1998

Faculty Development in Technology Applications to University

Instruction: An Evaluation

Margie K. Kitano

Bernard J. Dodge

Patrick J. Harrison

Rena B. Lewis

Follow this and additional works at: https://digitalcommons.unl.edu/podimproveacad

Part of the Higher Education Administration Commons

Kitano, Margie K.; Dodge, Bernard J.; Harrison, Patrick J.; and Lewis, Rena B., "Faculty Development in Technology Applications to University Instruction: An Evaluation" (1998). To Improve the Academy. 408. https://digitalcommons.unl.edu/podimproveacad/408

This Article is brought to you for free and open access by the Professional and Organizational Development Network in Higher Education at DigitalCommons@University of Nebraska - Lincoln. It has been accepted for inclusion in To Improve the Academy by an authorized administrator of DigitalCommons@University of Nebraska - Lincoln. 
Kitano, M. K., Dodge, B. J., Harrison, P. J., \& Lewis, R. B. (1998). Faculty development in technology applications to university instruction: An evaluation. In M. Kaplan (Ed.), To Improve the Academy, Vol. 17 (pp. 263-290). Stillwater, OK: New Forums Press and the Professional and Organizational Development Network in Higher Education. Key Words: active learning, education, evaluation, faculty development, instructional technology.

\section{Faculty Development in Technology Applications to University Instruction: An Evaluation}

\section{Margie K. Kitano}

\section{Bernard J. Dodge}

\section{Patrick J. Harrison}

\section{Rena B. Lewis}

San Diego State University

Progress in integrating new technologies into higher education classrooms has been slow despite emerging evidence on benefits for students when technologies are applied in ways that support teaching and learning. This article describes a program used by a college of education to support faculty applications of technology in instruction and reports results of a formal evaluation following the first year of implementation. The program provided intensive training and followup support to a heterogeneous cohort of 14 faculty members and was designed to enhance their ability to integrate technology into their teaching, use a new "smart" classroom facility, and/or develop products for instruction. Evaluation data were collected from program 
participants, their students, and the general faculty as a comparison group. Purposes of the evaluation were to determine the extent and quality of participants' applications of technology in their courses, other effects on their professional development, and students' perceptions of impact. Results demonstrate the program's efficacy for increasing participants' integration of technology in instruction. Students reported that these instructors' applications of technology enhanced students' learning and confidence in using technology.

While the private sector has been quick to embrace technology innovations, critics depict professional educators as unnecessarily slow in their implemention of applications to teaching and learning. Recent articles in The Futurist, for example, adopt adversarial metaphors in describing the relationship between technology and education. Pelton (1996) portrays technology in the higher education arena as "Cyberlearning vs. the University: An Irresistible Force Meets an Immovable Object." Snider's (1996) analysis of the K-12 situation ("Education Wars") begins by announcing that "New information technologies will transform education, but only after a battle royal with the education establishment" (p. 24).

Indeed, over 75 percent of U.S. undergraduate education continues to follow traditional lecture/discussion/textbook methods; only 15 percent of faculty currently use information technology in instruction (Gilbert, 1996). Technology integration at the K-12 level appears to be at a similar stage. A national survey indicates that while 65 percent of U.S. public schools had access to the Internet in fall 1996, only 14 percent of all instructional rooms had such accéss, and 20 percent of public school teachers were using advanced telecommunications for instruction (National Center for Education Statistics, 1997).

Gilbert (1996) identified the difficulty of altering teaching methods as one of several obstacles to integrating technology in university instruction:

Most faculty members are busy people who have never observed others teach effectively using information technology. It is unrealistic to expect any human being to replace-quickly, easily, and without help-habitual behaviors based on years of observing others who have used the same old (teaching) model. (p. 11) 
Overcoming such inertia is critical for all higher education disciplines and particularly for colleges of education responsible for preparing teachers for the $\mathrm{K}-12$ schools. This article describes a program used by one college of education to support faculty application of technology in instruction and provides an evaluation of initial results. Both the program and evaluation have wider application to faculty development across disciplines. The article begins with a brief review of literature followed by a description of the faculty development program, evaluation design, results, and implications.

\section{Literature Review}

Three areas of literature informed the design and evaluation of the training program: the impact of technology on student achievement, effective practices for faculty development, and technology training and evaluation. The following literature review is not intended to be exhaustive but to summarize current knowledge relevant to the evaluation project.

\section{Impact of Technology}

The popular media's praise of new technologies and criticism of educators' progress in their adoption presume that information technologies will improve student achievement. Yet, empirical research documenting technology's effects on teaching and learning is limited. A recent review of research on the impact of technology on K-12 education indicates that technology does not itself directly affect learning (Birman, Kirshstein, Levin, Matheson, \& Stephens, 1997). Rather, increased student achievement can result from technology's capacity for improving the teaching and learning process. Several studies reviewed by Birman et al. (1997) suggest that technologies applied in ways that support teaching and learning can increase K-12 students' motivation, academic performance, engagement in higher order thinking, and quality of products. Additionally, technology can improve teaching practices by supporting teachers' efforts to incorporate authentic and collaborative learning and to encourage greater student control over their own learning. Given the integral relationship among student outcomes, teaching and learning, and technology, 
Birman et al. conclude that evaluations of technology's effects must examine all aspects of the educational environment.

\section{Faculty Development}

A large knowledge base exists on effective training and faculty development practices in general. Recent syntheses of literature (Chiero, 1995; Cranton, 1994) suggest that effective professional development programs have a number of common features. First, they respect and build upon the existing knowledge base of participants. Second, they involve participants in planning and designing of training, developing personal action plans, and goal setting. Third, they apply research-supported training practices, including use of credible experts and facilitators, collaborative work groups, participant-centered learning, peer consultation, use of participant expertise, and relevant readings. Fourth, they incorporate a 4-phase structure of theory and research, modeling/demonstrations, practice with feedback, and peer coaching during implementation. Finally, effective professional development programs employ strategies to institutionalize change, including obtaining the support and participation of administrators; conducting training over time as opposed to one-shot workshops; providing for follow-up, accountability, and rewards; and building capacity through training a critical mass and developing leadership.

\section{Technology Training and Evaluation}

The need to apply technologies in ways that support teaching and learning requires that higher education instructors model effective applications and encourage appropriate use by preservice educators. A literature is beginning to emerge describing models for integrating technology into higher education in general (e.g., Gilbert, 1996) and professional education curricula in particular (e.g., Barker, Helm, \& Taylor; Topp, Mortenson, \& Grandgenett, 1995). However, few formal evaluations appear to be available.

Gilbert (1996) emphasized that universities must support and encourage faculty members to stay current with instructional methods as they do with content in their fields. But "none of this can be 
accomplished through exhortation: equipment, time, incentives, training, and other support services are essential" (p. 16). He recommends developing an overall institutional strategy and a combination of narrow/deep and wide/shallow change strategies that include use of student assistants; electronic mail and instruction; collaborative learning and groupware; internal faculty grants; supporting early faculty adopters and engaging them as peer mentors; and exposing faculty to "irresistible combinations" of teaching approaches and technology that permit teaching and learning in ways that would otherwise be difficult or impossible. Openness of participants to adopting new technologies (Cervero \& Yang 1994), personal beliefs, and personality typologies (Rude-Parkins, Baugh, \& Petrosko, 1993) also may contribute to the success of training.

For increased use of technology in teacher training institutions, Topp et al. (1995) identified equipment, training, and organizationwide expectations as key elements. Training was designed around three levels: awareness (of potential uses and software), experience (opportunities to try out technology applications in a supportive handson environment), and integration (sharing how certain technologies might be used in instruction).

While there exists a large literature on evaluation of training in general (e.g., Kaufman, Keller, \& Watkins, 1996; Lincoln \& Dunet, 1995; Moseley \& Larson, 1994), less information is available on evaluating training in technology applications (Tucker, Dempsey, \& Strange, 1990). According to Jackson (1990), methods useful for evaluation research on learning technologies in higher education include surveys, interviews, observations, and activity measures. $\mathrm{He}$ emphasized the need for designs that link student experiences with learning technology and outcomes; observation and other measures that document change independently of self reports; and clear statements of program goals or research questions.

In sum, the literature indicates that new technologies can benefit students to the extent that technologies are integrated in ways that support teaching and learning. The potential positive impact of technologies at all levels of education underscores the need to develop and evaluate programs designed to enable higher education faculty, especially in colleges of education, to appropriately incorporate the new 
technologies in their courses. The general literature on training and faculty development describes the components of effective programs, emphasizing active participation of trainees, research-based strategies, and followup. The available literature on evaluating programs for training faculty in instructional applications of technology suggests the need for clear goals, use of multiple types of measures and sources of data, and comprehensive assessment of the educational context.

\section{Program Description}

In Fall 1993, the College of Education at San Diego State University, a large comprehensive institution, launched its Technology Initiative (TI) designed to support professional development, improve instruction and preparation of education professionals, and build capacity for leadership in instructional technology. Activities included those designed to provide exposure to large numbers of faculty regarding the potential of technology to improve teaching and learning (wide/shallow strategy) and to develop the skills of a smaller cohort of faculty members across departments in implementing technology in one targeted course (narrow/deep). Activities for large numbers of faculty included sponsoring of college- and university-wide demonstrations and workshops supported by individual coaching for faculty members, mini-grants for faculty-initiated projects, and creation of technology-related community partnerships through internal and external funding. The main narrow/deep strategy, the TI Fellows Program, commenced in Spring 1996 and serves as the focus of the evaluation.

\section{Background and Goals}

In Spring 1996, the university allocated resources to provide each college with at least one "smart" (technology-rich) classroom. Based on faculty input, the College of Education designed its facility to include a presentation station, eight student workstations positioned around the edges of the room, and tables and chairs in the center. The configuration allows for both a traditional instructor-centered class as well as for more innovative modes of instruction based on students working in groups around a computer (e.g., accessing data on the 
Internet; collaborating on the creation of computer-based material). The presentation station includes a Power Macintosh, VCR, videodisc player, document camera (ELMO), and a projector unit allowing the display of both video and computer output. A second presentation station was purchased as a portable unit to be used in standard classrooms.

The TI Fellows Program was developed primarily to prepare a cadre of faculty to teach at least one course ("targeted course') each in the smart classroom during the following academic year, utilizing the classroom's technology resources to support learner-centered instruction. Training was designed to enhance the ability of participants to (a) integrate technology into instruction, (b) use the College's smart classroom facility, and/or (c) develop products for instruction.

\section{Participants}

Twelve tenured or tenure-track faculty members initially were selected as Fellows by their respective Chairs based on interest in and commitment to incorporating technology into instruction. Prior to training, two additional faculty members were added by petitioning to the Dean. The final 14 represent five departments: Administration, Rehabilitation, and Postsecondary Education; Counseling and School Psychology; Policy Studies in Language and Cross Cultural Education; Special Education; and Teacher Education. Faculty and staff from the College's sixth department, Educational Technology, provided leadership and training for the program.

The Fellows were diverse in race and gender, with eight women (one African American, one Latina, six White) and six men (four Latino and two White). By rank, they included two assistants, five associates, and seven full professors. Fellows also were heterogeneous with regard to initial level of expertise with technology, defined by the project along four levels based on those described by Topp et al. (1995): awareness of potential uses and software; experience in trying out applications in a supportive (e.g., workshop) environment; implementation in instruction; and integration/transformation to the extent that the course cannot be taught without technology. Interview data indicated that at the program's inception, half the Fellows rated 
themselves at the lower two stages ( 4 at awareness; 3 at experience) and half at the higher two stages ( 3 at implementation and 4 at integration/ transformation). Baseline data corroborated this self-assessment, indicating that six had not integrated technology in their courses with the exception of computer-generated transparencies, content-related software, and instructional video.

During the spring semester, two orientation meetings were held to determine Fellows' goals and needs with respect to the types of applications that would support course content and objectives. The orientation meetings demonstrated a range of interests, content areas, and levels of technology sophistication. Yet, the meetings permitted identification of a core of applications that would be useful to this group: videoteleconferencing; instructional uses of the Internet (email, WWW, chat rooms, newsgroups, development of web pages, putting syllabi and assignments on the Web); software for collaborative work and lesson plan development; and creation and use of products (e.g., videotapes, multimedia).

Based on this assessment, software and hardware were purchased to equip all workstations in the smart classroom with Apple's QuickTime desktop videoconferencing software; Netscape for accessing the World Wide Web; Aspects software for collaborative work and group polling; Inspiration for brainstorming and concept mapping; HyperStudio for multimedia development; Planalyst for developing and evaluating lesson plans; WebWeaver for creating web pages; and PowerPoint for enhancing presentations.

The same software programs purchased for the smart classroom, plus a zip drive, were installed on each Fellow's office workstation to support familiarity and use ${ }^{1}$. Each faculty member also was offered a modest stipend ${ }^{2}$ to acknowledge the importance of her or his time and efforts in redesigning their courses over the summer for Fall or Spring implementation in the smart classroom.

\footnotetext{
${ }^{1}$ The software and hardware purchased for this first cohort of Fellows totaled $\$ 670$ per Fellow. With rapid improvements in software development and availability plus upgrades in the standard workstation issued to faculty members, those costs were reduced to $\$ 135$ by the third cohort, for whom only Claris Homepage and Inspiration were purchased.

${ }^{2}$ Each Fellow in the first cohort received a $\$ 1,000$ stipend, reduced to $\$ 500$ for subsequent cohorts.
} 


\section{Training}

Training occurred at the end of Spring semester and consisted of a 5-day intensive workshop tailored to Fellows' expressed interests and objectives as identified through the orientation meetings. Fellows were also given the opportunity to attend a 3-day institute on distributed course delivery and problem-based learning held on the campus the following week. Fellows were encouraged to attend all projectbased training. However, their accountability focused on achievement of the project's goals rather than participation in formal training. Nevertheless, only one Fellow did not participate in any of the training.

Consistent with literature (Gilbert, 1996; Topp et al., 1995) training was learner-centered and based on participants' self-identified needs. The intensive workshop addressed potential uses of software, demonstrated applications, and provided opportunities to use software and develop applications in a supportive environment. The intensive training week began with a welcome by the Dean, who emphasized the importance of Fellows' work as pioneers with the smart classroom and encouraged creativity, experimentation, and risk taking. Content included an introduction to the smart classroom; use of the various software programs; camcorder basics and use of educational video; scanning and digitizing; and strategies for teaching using Internet tools (newsgroups, chat rooms, electronic data collection). Opportunities for individual and small-group consultations with experts were provided, and Fellows were asked to develop and post individual action plans on the Web. Instruction and follow-up support over the summer and continuing through the academic year were provided by Educational Technology faculty, the College's systems analyst, and coaches (Educational Technology graduate students hired to provide all faculty with individual and group consulting on technology applications to instruction). At the Fellows' request, monthly meetings were held during the academic year to identify and solve problems, share strategies, receive updates, and demonstrate Fellow-developed lessons and products. 


\section{Evaluation Design}

The literature highlights the recency and complexity of efforts to understand the change process in faculty adoption of technology applications to instruction. Within this context, a combination of objectives-oriented and qualitative approaches (Patton, 1980; Worthen \& Sanders, 1987) appeared most appropriate for the evaluation goals of documenting faculty development and technology applications and identifying elements supportive of change. A constructivist approach to evaluation was chosen as consistent with the collaborative nature of the undertaking. TI Fellows and instructors reviewed and commented on the evaluation plan, developed simultaneously with the training program, and added a student survey to the data collection instruments.

\section{Purpose of the Evaluation}

The major purposes of the evaluation were to (a) document changes in terms of Fellows' professional development and technology applications in targeted courses and (b) understand factors that support implementation of technology applications. It was anticipated that this information would contribute to the College's capacity for motivating and sustaining further change. The perspectives of the Fellows themselves were of critical interest, given that the project was designed to be learner-focused within the constraints of schedules and resources. Continuation of the project would be determined primarily on the basis of resource availability. Hence, information generated by the evaluation was considered more critical for decisions regarding ways to improve experiences and outcomes for any subsequent cohorts of Fellows. The audiences for the evaluation findings include the Fellows, project designers, trainers, chairs, faculty, and the Dean.

Specific questions $(1,2)$ were articulated to address the evaluation's major purposes. Two additional evaluation questions $(3,4)$ were included to address issues raised in the literature and by the Fellows themselves.

1. What has been the impact of the Fellows Program in terms of (a) the extent to which Fellows incorporate technology into instruc- 
tion in the targeted courses; (b) the quality of their applications; and (c) other aspects of their professional work, including attitudes toward technology?

2. What factors do faculty (and students) identify as supporting and hindering their use of technology?

3. What is the perceived impact, if any, on students who receive instruction from Fellows in the smart classroom?

4. Does incorporating technology in instruction have social value?

\section{Instruments and Samples}

Five procedures were used to collect data from multiple sources to address the evaluation questions.

Pre-training questionnaire. A brief questionnaire was completed by the 14 Fellows prior to the 5 -day intensive training. The form requested a description of technology applications currently used in course instruction and plans for using technology in the course targeted for the smart classroom.

Observations. Fellows were asked to invite the Associate Dean responsible for staffing the program to observe a session taught in the smart classroom during the first semester of implementation. The purpose of the observation was to document use of smart classroom technology in instruction and the integration of the technology with course content objectives. Of the 14 Fellows, eight invited observations and seven observations actually were conducted. Four additional Fellows provided demonstrations of applications at Fellows' monthly meetings.

Interviews. The Associate Dean also interviewed each Fellow individually at the end of the first semester of course implementation in the smart classroom. Questions were designed to determine Fellows' perceptions of the impact of the TI Fellows Program, including completion of individual objectives, effects on teaching, examples of applications used, most and least useful program elements, future goals, and perceptions about the potential of technology applications in teaching for contributing to the good of society in general.

Faculty activity survey. A Faculty Activity Survey was designed to assess level of participation in technology-related activity; integra- 
tion of technology in professional work; factors supporting development of knowledge and skills related to technology; obstacles to applying technology in instruction; perceptions of personal change with regard to technology; perceived impact on students; and estimated level of technology integration in the classroom. The Faculty Survey was sent to all tenured and tenure-track faculty in the College at the end of the first year of the Fellows Program. Of the 69 faculty members not on leave, 44 (28 general faculty, 11 Fellows, and 5 Educational Technology faculty) responded for an overall return rate of $64 \%$. By department, return rates ranged from $50 \%$ to $71 \%$. For purposes of this evaluation, responses were compared across three groups of respondents: general faculty, Fellows, and Educational Technology faculty.

Student survey. A Student Survey containing items similar to those in the Faculty Survey was developed to address obstacles to student use of technology, perceptions of personal change from technology used in the classroom, and level of use before and after taking a course in the smart classroom. Eight Fellows representing four programs (teacher education, special education, policy studies, and administration/rehabilitation) administered the Student Survey at the end of the semester to students in the first course they taught in the smart classroom. A total of 135 primarily post-baccalaureate (credential, master's, and doctoral) students completed the survey.

\section{Results}

All fourteen Fellows identified a target course to be taught in the smart classroom or to be revised to integrate technologies within a typical classroom setting. One Fellow did not teach her targeted course due to a change in assignment (from teaching to administration). For some, scheduling difficulties, the availability of only one smart classroom, and participation in site-based programs (programs taught on a public school campus) limited the number of sessions that could be held in the smart classroom. Nevertheless, eleven Fellows held at least three sessions of their targeted class in the smart classrooom during the subsequent academic year. The remaining two Fellows taught their targeted courses in typical classrooms either on the university campus 
or at a public school site. The technology labs and portable instructor's platform provided additional technology access.

\section{Extent and Quality of Technology Implementation}

The first evaluation question focused on the extent and quality of Fellows' use of technology in courses they targeted for technology integration during the first semester of smart classroom use. This question was examined in terms of amount of time they spent on technology in the course; in-class observations; Fellows' self-assessment of their progess; and faculty assessment of the level of technology integration in their courses.

Amount of time. The Faculty Survey indicated that $72.7 \%$ of the responding faculty members reported spending more class time using technology over the course of the 1996 calendar year. However, compared to the general faculty, Fellows added to their courses a significantly greater $(p<.01)$ percent of time using technology applications. Of those who gave percent increases, Fellows (9) reported an average increase of $27.4 \%$ of time using technology in their courses and general faculty (15) $10.5 \%$. Technologies infused into courses included e-mail, teleconferencing, various types of Internet searches, audiovisual resources, PowerPoint presentations (by faculty and students), and software (mathematics, Planalyst, Inspiration, SPSS, Excel, Hyperstudio).

Observations. As would be expected by the invitational nature of the observations, all seven classes observed in the smart classroom provided opportunities to observe Fellows and students using one or more technology applications. Nevertheless, the observations confirmed that Fellows did incorporate technology applications covered in the intensive training. The observations also indicated that faculty members adapted these applications to their own styles and methods of teaching as well as to the course's content. For example, a faculty member teaching a mathematics methods course incorporated a learning centers approach. She divided the class into three simultaneously operating groups: one creating lesson plans using Planalyst software at the workstations; one observing at the workstations in preparation 
for their turn at the computer; and one group sitting at the tables to review for an upcoming exam.

A second Fellow, teaching a bilingual methods course, used a cooperative learning "jigsaw" structure in which each small group was asked to become an expert on a different chapter in a text and present a summary of their chapter to the whole group. Within the groups, each member was asked to become an expert in one of six software programs (PowerPoint, Inspiration, etc.). Each group would then determine which software programs to apply in developing their presentations.

Observations also indicated that Fellows worked to build new skills demanded by use of technology. A Fellow teaching a bilingual special education course encouraged his preservice teachers to teach their students how to work on several tasks at once so that they can effectively use the "downtime" available while students wait for websites to come up. A fourth Fellow encouraged her preservice teachers to become advocates for access to technology in K-12 schools.

Other activities observed included preservice teachers building their own web pages as part of their professional portfolio; educational psychology students brainstorming and concept mapping (using Inspiration) as a way of illustrating cognitive processing; bilingual preservice teachers delivering technology-supported presentations to the whole class using the presentation station; and special education graduate students conducting structured Internet searches for information needed to defend political platforms on education.

Four additional Fellows gave demonstrations of their self-designed classroom applications during the monthly Fellows' meetings. These presentations included on-line procedures for establishing student e-mail accounts; a multi-media product to support student development of basic statistical concepts; an Internet-based resource to enhance students' fluency in Spanish language and culture; and an application of groupware in the preparation of educational administrators. These observations and presentations indicate how well the faculty members integrated technology with course objectives, values, content, and instruction.

Self-assessment of progress. On the interviews, four Fellows reported meeting their initial objectives for the Fellows Program and 
all reported making progress. All but two described themselves after one semester following training as being at the third (implementation) or fourth (integration/transformation) stage of technology use in instruction. Of the two exceptions, one noted that her appointment as department chair immediately following training precluded her teaching. Even this Fellow assessed herself as having moved a stage and a half along the continuum on the basis of the training. The second, who had access to the smart classroom only for three class sessions, felt that greater opportunity to use the facility would have resulted in greater growth.

One pre-determined quality indicator was the use of technology to support learner-centered instruction as opposed to enhancing instructor presentations (e.g., through PowerPoint). Several Fellows used software to enhance their presentations as one application. Only one Fellow (the one who did not attend the intensive workshop) reported using the smart classroom primarily to enhance instructor presentations (multimedia presentation of concepts) as opposed to involving students actively in using technology to support their learning. Results of student surveys corroborated the lack of integration of other technologies in this one course.

Level of technology integration. The Faculty Survey asked faculty members to describe how they and their students used technologies in their most technologically integrated course. A clear trend was found relating instructors' technology expertise to level of instructor and student use. General faculty were more likely to report little to occasional use of technology in course preparation and delivery, sporadic use by students, and limited integration of technology in the curriculum. TI Fellows reported regular use of technology for engaging students in active learning, regular and comprehensive use by students, and a technology dependent curriculum. Educational Technology faculty described regular and comprehensive use in course preparation and delivery; comprehensive use by students, who could not meet course outcomes without technology; and inability to implement courses without technology. 


\section{Impact on Faculty}

Impact on faculty was analyzed based on two measures: perceptions of personal change and extent of technology used in professional work prior to and after the first year of the Fellows Program.

Faculty self-perceptions. Survey items assessing changes in self perceptions used a Likert scale: strongly disagree (1), disagree (2), agree (3), and strongly agree (4). T-tests comparing general faculty and Fellows on the Faculty Survey indicated that Fellows had significantly $(p<.05)$ stronger self-perceptions regarding their use of technology. Fellows indicated stronger agreement regarding increased knowledge and skills in applying technology to instruction (mean for Fellows $=3.64$; for general faculty $=2.81$ ); the ability of their courses to prepare prospective professionals to use technologies in appropriate ways $(3.73 ; 2.30)$; changes in their instructional strategies to more learner-centered approaches $(2.73 ; 1.98)$; and increased sharing with colleagues as a result of their participation in College technology activities $(3.50 ; 2.29)$. The two groups did not differ significantly in terms of increased self-confidence $(3.36 ; 2.88)$. Respondents as a whole indicated that they had developed more confidence in their ability to use technologies to support instruction.

Impact on professional work. The Faculty Survey asked respondents to compare the amount of reading, number of presentations or workshops attended, number of professional presentations given, amount of class time, research/writing related to technology themes, and variety of technology applications used for 1996 (the first year of the Fellows Program) compared to the previous year. Table 1 shows that a greater percentage of Fellows than general faculty members reported an increase in professional activities related to technology.

During individual interviews with Fellows, all indicated that participation in the Fellows program affected some aspect of their professional work. In addition to integrating more technology in instruction, individuals noted a desire to integrate technology in additional classes or in different ways; more awareness regarding the relationship between pedagogy and technology; improved presentations and organization of lessons; getting to know more colleagues and assisting colleagues with technology; advocating for technology 


\begin{tabular}{|l|c|c|}
\hline \multicolumn{3}{|c|}{ TABLE 1 } \\
Percent of General Faculty and Fellows Reporting \\
Increased Professional Activity Related to Technology \\
\hline \multicolumn{3}{|c|}{ Percent Indicating Increase Over Previous Year } \\
\hline \multicolumn{1}{|c|}{ Professional Activity } & General Faculty $(\mathrm{n}-28)$ & Fellows ( $\mathrm{n}=11)$ \\
\hline Reading & $63.0 \%$ & $100 \%$ \\
\hline No. of presentations attended & $59.3 \%$ & $70.0 \%$ \\
\hline No. of presentations given & $22.2 \%$ & $54.5 \%$ \\
\hline Class time on technology & $66.7 \%$ & $90.9 \%$ \\
\hline Research and writing & $19.2 \%$ & $54.5 \%$ \\
\hline Variety of applications & $59.3 \%$ & $90.9 \%$ \\
\hline
\end{tabular}

in the schools; and engaging in scholarly activity relating technology and their own field (e.g., giving a national conference presentation on teaching and learning of cultural and linguistic competencies through technology; writing a chapter on technology applications to research and writing; developing a grant proposal involving technology applications).

Faculty perceptions of impact on students. The Faculty Survey also asked respondents to indicate the degree to which they believed that use of technology in education courses resulted in increased attendance, completion of assignments, academic performance, engagement in problem solving, interest and motivation, time engaged in assigned work, initiative and proactivity, collaboration, and application of technology in the field. Possible ratings were not at all (1), moderately (2), and significantly (3). A comparison of general faculty and TI Fellows indicated a significantly $(p<.05)$ stronger belief among Fellows that technology applications increase students' engagement in problem solving $(2.45 ; 1.91)$, time engaged in assigned work (2.50; $1.79)$, and initiative/proactivity $(2.50 ; 1.83)$. Both groups perceived highest increases in students' application of technology in the field $(2.64 ; 2.35)$ and the least impact on attendance $(1.60 ; 1.38)$. 


\section{Impact on Students}

The impact on students who took classes taught by Fellows in the smart classroom during the first semester of implementation was assessed by analyzing student reports of change through several items on the Student Survey.

Students (135 total) surveyed in eight classes taught by Fellows in the smart classroom represented a heterogeneous group with regard to their prior experience with computer technology. Over half (54.3\%) of the credential students and nearly half $(45.0 \%)$ of the master's students reported that their first experience using the Internet for research was in their smart classroom course. Under half of the credential students $(47.2 \%)$ and most $(86.7 \%)$ of the graduate students had used e-mail prior to the course.

Perceived impact of Fellows' incorporation of technology. Table 2 indicates the percentages of students who agreed or disagreed with statements regarding the effect of Fellows' use of technology in the smart classroom.

Responses to additional items indicated that nearly all students (96.2\%) strongly agreed or agreed that appropriate applications of technology enhance learning. The vast majority (95.5\%) also strongly agreed or agreed that being able to use technology appropriately is important to their field. Over 80 percent of students surveyed reported that they developed greater confidence, knowledge, and skills, and increased preparation to use technologies as a result of their instructor's incorporation of technology in the smart classroom. Most are sharing or planning to share with colleagues their growing expertise in technology. Several students' written comments indicate the level of their enthusiasm: "I would like to have access to courses who [sic] use technology as a regular mode of presenting information. The instructor's station, coupled with collaborative/cooperative work groups is a very effective strategy." "This sort of technology should be made available in more of the coursework."

Students were also asked to rate the degree (not at all $=1$; moderately $=2$; significantly $=3$ ) to which they believed their own behaviors were influenced by use of technology in their course: attendance, completion of assignments, learning of course content, academic 
performance, engagement in problem solving, interest and motivation, time engaged in assigned work, initative and proactivity, colloborative work in groups, and application of technology in the field. As a whole, students reported most impact on interest and motivation (2.35) and application in the field (2.18) and least on attendance (1.58) and academic performance (1.78).

The Student Survey also asked students to estimate their general use of computer technologies and use of eletronic information resources prior to and upon completion of the class. The scale ranged from 1 (rare use) to 4 (dependency on technology). Less than half $(41.6 \%)$ reported a positive $(+1,2$, or 3$)$ change in general technology use and $37.4 \%$ a positive $(+1$ or 2 ) change in use of electronic information resources. Of those reporting no change, $18.3 \%$ were due

\begin{tabular}{|c|c|c|c|c|}
\hline \multicolumn{5}{|c|}{$\begin{array}{c}\text { TABLE } 2 \\
\text { Percentages of Students }(n=135) \text { Agreeing or } \\
\text { Disagreeing to Possible Effects of Fellows' Use of } \\
\text { Technology in Instruction }\end{array}$} \\
\hline Statement & $\begin{array}{c}\text { Strongly } \\
\text { Agree }\end{array}$ & Agree & Disagree & $\begin{array}{l}\text { Strongly } \\
\text { Disagree } \\
\end{array}$ \\
\hline $\begin{array}{l}\text { As a result of instructor's } \\
\text { incorporation of technology in class, } 1 \\
\text { have developed more confidence in } \\
\text { my ability to use technologies. }\end{array}$ & 45.0 & 43.4 & 7.8 & 3.9 \\
\hline $\begin{array}{l}\text { As a result.. my knowledge and skills } \\
\text { in applying technology have } \\
\text { increased. }\end{array}$ & 48.8 & 41.1 & 7.0 & 3.1 \\
\hline $\begin{array}{l}\text { As a result... I am better prepared to } \\
\text { use technologies in my professional } \\
\text { work. }\end{array}$ & 43.1 & 38.5 & 13.1 & 5.4 \\
\hline $\begin{array}{l}\text { As a result. . J am sharing or planning } \\
\text { to share my growing expertise in } \\
\text { technology applications with peers. }\end{array}$ & 29.5 & 41.1 & 22.5 & 7.0 \\
\hline $\begin{array}{l}\text { It is important for students in my field } \\
\text { to be able to use technology } \\
\text { appropriately. }\end{array}$ & 69.5 & 26.0 & 3.8 & 0.8 \\
\hline $\begin{array}{l}\text { Learning is enhanced by appropriate } \\
\text { applications of technology. }\end{array}$ & 70.0 & 26.2 & 3.1 & 0.8 \\
\hline
\end{tabular}


to a ceiling effect (giving a 4 on use prior to and at the end of the course) and $34.1 \%$ potentially to a floor effect (giving a 1 for both time periods). Small but significant $(p<.05)$ correlations were found between magnitude of change and perceptions of impact on academic performance $(r=.27)$; completion of assignments $(r=.19)$; initiative and proactivity $(\mathrm{r}=.29)$; learning of course content $(\mathrm{r}=.23)$; application of technology in the field $(r=.25)$; and interest and motivation $(r=.28)$.

\section{Obstacles, Implementation Problems, and Supporting}

\section{Factors}

Obstacles. Faculty as a group rated insufficient time to learn about and develop applications as the greatest obstacle to applying technologies in instruction (relative to other listed items). 54.5\% considered lack of time a major obstacle; only $9 \%$ did not consider time an obstacle. Nearly one-third (31.1\%) considered access to equipment, facilities, and software a major obstacle. Lack of relevance to courses taught and belief in the superiority of traditional modes of instruction were not considered obstacles. No significant differences were found between general faculty and TI Fellows regarding perceived obstacles except that general faculty rated discomfort with technology as a minor obstacle, while Fellows did not consider discomfort as an obstacle in any sense. In contrast, students rated insufficient access to equipment, software, and facilities as the greatest obstacle to their continued use of technologies after course completion.

Supporting factors. As a whole, faculty rated most highly the following items as factors that support development of knowledge and skills related to technology: belief in need for students to be competent in technology; belief in the potential of technology to improve learning; and software/hardware. While the above were rated "essential," "contributing factors" included coaches, collaboration with colleagues, labs, assigned time, consulting with experts, and smart classrooms. As a whole, faculty described stipends as a minor factor.

Significant differences were found between general faculty and Fellows on their ratings of four items. Fellows rated assigned time, the Fellows Workshop, and the smart classroom as essential, whereas the general faculty were more likely to rate these three items as contrib- 
uting or minor. At least two of the Fellows expressed support for the concept of coaches but felt that the coaches (graduate students in Educational Technology) needed a higher level of knowledge and skills. These differences were not surprising, given that Fellows had exclusive access to the workshop and primary access to the smart classroom. The general faculty rated collaboration with colleagues more highly as a supporting factor than did Fellows.

Open-ended comments suggested that at least one general faculty member found the Fellows Program an obstacle itself because of its lack of inclusiveness. This issue has been resolved through offering of training to additional cohorts, open to all faculty. Two respondents from the general faculty identified mentoring relationships with a colleague as the most influential factor in their learning. Noted one: "I wasn't trained as a TI Fellow but had the opportunity to use the smart classrom with a colleague who is a Fellow. The possibilities really fascinated me: group learning, critical analysis opportunities for examining information on the WWW; additional inquiry skills."

Implementation problems. Interviews with Fellows and issues raised at their monthly meetings reveal a variety of problems encountered in the first semester of technology implementation in teaching. These can be categorized as infrastructure, procedural, conceptual, and student issues.

An initial infrastructure problem related to the smart classroom was the narrow band width serving the facility. This problem resulted in lengthy waiting periods for accessing Internet sites as well as crashing of computers during attempts to use multiple workstations for desktop teleconferencing. (Most students, however, rated unreliability of equipment as "not an obstacle" or as a minor one). A second problem concerned inconsistency of software versions used in the smart classroom and student labs and incompatibility of software installed in the smart classroom (all MACs) and software available to PC-using Fellows and students. Additional frustrations emerged from limited access to documentation due to purchases of site licenses for software (as opposed to individual purchases for each Fellow) and increased use of technology labs by less sophisticated students.

A major infrastructure problem arose from the availability of only one smart classroom in conjunction with the needs of post-baccalau- 
reate education programs to offer courses after 4:00 p.m. Several Fellows had to share the smart classroom, reducing the number of sessions taught with technology and causing some confusion among the students. Having only one facility limited most Fellows to teaching only their target course in the smart classroom:

I designed a new course which incorporated extensive technology. This next semester, I don't have the hardware to carry out the course because of access to the smart classroom. I am now having to revise significantly my course.

Another major infrastructure problem was lack of technology resources in the public schools where the College operates site-based teacher preparation programs. The dual emphases on site-based instruction and technology applications to instruction will compete until the K-12 schools become equipped with similar technologies or the college relocates its programs to different sites. Fellows serving site-based programs needed to require students to go to the university for instruction, thereby defeating the objective of site-based training:

I can best use technology only on campus where the smart classrooms and labs are located. As soon as I go off campus to teach classes, I am back in a very traditional teaching mode because the tech resources are not available. At the present time, holding classes off campus short changes students by eliminating any meaningful tech-related experiences. I have partially "solved" this problem through compromise-I hold several of my on-site classes sessions at SDSU when tech resources are needed; but this is not a good solution to this problem. It poses problems for students; parking, scheduling-it basically is confusing.

Procedural problems included each class progressively adding files to the desktop on workstations in the smart classroom, finding the printer empty of paper, rearranging the room setup, and inconsistently following security precautions. Once identified, these types of issues were easily problem-solved by the group. The major conceptual issue identified by Fellows was the need for a more coherent conceptual framework for the Fellows Program. While loosely based on the premise of establishing a community of learners, in effect Fellows tended to work individually rather than collaboratively, despite efforts to formalize smaller groups focused around specific content or media. 
The two major student-related issues concerned heterogeneity of technology-related skills and many students' lack of access to computers off campus with compatible software. Most Fellows found a need to teach the technology and support students' comfort with it, decreasing the amount of class time available for content instruction. This problem may diminish as students receive more computer experience during the $\mathrm{K}-12$ and undergraduate years; alternatively, a prerequisite course may be designed to introduce students to required technology applications.

\section{Social Impact}

Because of the failure of many evaluation plans to consider the social value of the program being evaluated (Kaufman, Keller, \& Watkins, 1996), individual interviews with Fellows included a question concerning the potential of the Fellows program to contribute to the good of society in general. Most Fellows answered this question in terms of the potential impact of technology in general. They agreed that social changes due to technology are inevitable and bring the potential for both good and bad: "Like any technology, these can be used to deliver food or guns." The major positive aspects cited were opening of worldwide communications, including opportunities to practice second languages; rapid access to more information; and the possibility of glimpsing multiple perspectives.

Major concerns regarding negative potential included a widening gap between the information elite and information poor; the demise of the profession through distance delivery; diminishing of interpersonal skills and time spent among families and with other people. Fellows described a need for education regarding responsibility, ethics, and standards in use of electronic technologies. Specific to the Fellows Program, the general consensus seemed to be that because widespread use of technology is inevitable, universities have an obligation to enable faculty to prepare students to use technology in ways that improve the human condition. 


\section{Discussion and Implications}

Within the context of a college-wide effort to raise faculty expertise in technology applications, this evaluation study demonstrates the efficacy of one narrow-deep strategy for integrating technology into instruction. The strategy consisted of identifying a motivated and heterogeneous cohort of fourteen faculty members and enhancing their expertise through provision of intensive training, hardware and software, smart classroom access, and continued opportunities for support. The data indicate positive impact as perceived by participating faculty and their students. Findings regarding effects on students should not be generalized beyond education students, as their professional goals have specific relationships to the integration of technology and instruction.

However, the results of this evaluation have broader implications for faculty development programs in higher education, as the processes of training and integrating technology into instruction apply across disciplines. First, a narrow and deep strategy of intensive training and support of a cohort of motivated faculty can result in greater applications of technology in courses. A cohort may provide a critical mass of faculty needed to initiate substantive change in a college's curriculum through their own implementation efforts and their mentoring of colleagues. Additional benefits include increased scholarly activity related to technology and applications of technology beyond the initial "infused" course. Second, provided with training focused specifically on technology applications that enhance effective teaching and learning, faculty do integrate technology in ways that support content objectives and learner-centered instructional strategies.

Third, faculty motivation to acquire technology competence and prior use of learner-centered methods may be more critical in their selection than evidence of early adoption. This finding is consistent with studies on the relationship between personal beliefs about the need to acquire new knowledge and participation in continuing education. Heterogeneity of the cohort with respect to technology competence may provide novices with additional models, mentors, and incentive. Awareness activities for faculty as a whole should empha- 
size the knowledge base concerning the potential impact of technology applications on students' self-confidence, knowledge acquisition, and academic performance.

Training faculty to integrate technologies into their courses in the absence of adequate access to facilities that support their efforts causes immense frustration and obviously places external limits on implementation. Creation of smart classroom facilities in the absence of faculty prepared to effectively use these resources also makes little sense. Facilities and faculty development must occur in tandem and receive continued support for growth. As an example, following this evaluation, the college initiated two new directions. The first was to train a second cohort of faculty with the additional goal of developing applications for use in more typical classrooms, such as those with only one or no computer. The second involved creating additional, campus-based smart classrooms and collaborating with school partners in the site-based programs to develop smart classrooms at the sites.

As this manuscript goes to press, training for a third cohort has been completed; a new, dual-platform (Macintosh and PC) smart classroom has been approved (the college's third on-campus facility); the first site-based smart classroom has been initiated in a collaborating elementary school and positively evaluated; and a second sitebased smart classroom approved. The first cohort of Fellows showcased actual instructional examples to the third cohort as part of the most recent training. Their demonstrations provided creative inspiration to their colleagues and indicated continued growth. Applications included interactive, Web-based assessments; whole courses developed for distributed delivery; and problem-based learning modules covering a variety of content (e.g., history and characteristics of culturally diverse groups) using multimedia.

Evaluation of faculty development programs is critical to provide decision-makers with information that will help ensure effective and efficient use of the substantial resources required to enhance competence in applying technology in ways that support teaching and learning. And evaluation studies can support improvement and expansion of effective efforts. In-class observation of faculty applications to instruction constitutes a useful strategy for determining quality of 
integration and student response. Multiple sources of data, including observations, faculty and student surveys, and interviews, support reliability and validity of findings.

\section{References}

Barker, B. O., Helm, V., \& Taylor, D. R. (1995, February). Reforming teacher education through the integration of advanced technologies: Case study report of a college model. Paper presented at the 47th annual meeting of the American Association of Colleges for Teacher Education, February 1995. Macomb, IL: Western Illinois University (ERIC Document Reproduction Service No. ED 379 274)

Birman, B. F., Kirshstein, R. J., Levin, D. A., Matheson, N., \& Stephens, M. (1997). The effectiveness of using technology in K-12 education: A preliminary framework and review. Washington, DC: U.S. Department of Education Office of Educational Research and Improvement.

Cervero, R. M., \& Yang, B. (1994). Can Houle's typology of professionals predict participation in continuing education? The Journal of Continuing Higher Education, 42(3), 2-9.

Chiero, R. (1995). Effective training and development practices. Paper prepared for the Multicultural Education Infusion Center. San Diego, CA: San Diego State University.

Cranton, P. (1994). Self-directed and transformative instructional development. Journal of Higher Education, 65(6), 726-744.

Gilbert, S. W. (1996). Making the most of a slow revolution. Change, 28(2), 10-23.

Harvey, F. A., \& Nelson, A. (1995). A hybrid investigation of hypermedia training. (ERIC Document Reproduction Service No. ED 383 299)

Jackson, G. A. (1990). Evaluating learning technology. Journal of Higher Education, 61(3), 294-311.

Kaufman, R., Keller, J., \& Watkins, R. (1996). What works and what doesn't: Evaluation beyond Kirkpatrick. Performance \& Instruction, 35(2), 8-12.

Lincoln, R. E., \& Dunet, D. O. (1995). Training efficiency and effectiveness model (TEEM). Performance \& Instruction, 34(3), 40-47.

Moseley, J. L., \& Larson, S. (1994). A qualitative application of Kirkpatrick's model for evaluating workshops and conferences. Performance \& Instruction, 33(8), 3-5.

Pelton, J. N. (1996). Cyberlearning vs. the university: An irresistible force meets an immovable object. The Futurist, 30(6), 17-20.

Patton, M. Q. (1980). Qualitative cvaluation methods. Beverly Hills, CA: Sage.

Rude-Parkins, Baugh, \& Petrosko (1993). Teacher type and technology training. Computers in the Schools, 9(2/3), 45-54.

Snider, J. H. (1996). Education wars: The battle over information-age technology. The Futurist, 30(3), 24-28. 
Topp, N. W., Mortenson, R., \& Grandgenett, N. (1995). Goal: Technology-using teachers; Key: Technology-using education faculty. Omaha, NE: University of Nebraska. (ERIC Document Reproduction Service No. ED 385 240)

Tucker, S. A., Dempsey, J. V., \& Strange, J. H. (1990). Training university faculty to integrate hypermedia into the teacher training curriculum. Mobile, AL: Department of Behavioral Studies and Educational Technology, College of Education, University of South Alabama. (ERIC Document Reproduction Service No. ED 327 162)

Worthen, B. R., \& Sanders, J. R. (1987). Educational evaluation: Alternative approaches and practical guidelines. New York: Longman.

Contact:

Margie K. Kitano

Department of Special Education

San Diego State University

San Diego, CA 92182-1170

kitano@mail.sdsu.edu

Margie K. Kitano is Professor of Special Education and formerly Associate Dean for Faculty Development and Research in the College of Education at San Diego State University. She has been responsible for supporting faculty development initiatives in the College for the past ten years. Her publications focus on multicultural course transformation in higher education and the development of gifted potential in a diverse society.

Bernie Dodge co-directs the Teaching, Technology and Restructuring Partnership, an award-winning teacher preparation program based at two innovative schools. His professional focus is on the practical use of constructivist approaches to teaching with the internet as exemplified by the WebQuest model (http://edweb.sdsu.edu/webquest/webquest.html), which is being widely adopted by schools.

Patrick Harrison is chair of the Educational Technology Department at San Diego State University. His $\mathrm{PhD}$ from Michigan State University is in Instructional Design and Curriculum Development. Dr. Harrison teaches graduate evaluation, research design, and educational technology courses. He has directed the development of technological applications across disciplines, guided the initiation of technology use in the teacher education curriculum, and is an experienced consultant in management and evaluation.

Rena B. Lewis is Professor of Special Education at San Diego State University. Her research interests include use of technology in academic instruction for students with learning disabilities and others who experience difficulty acquiring basic skills. She currently is Director of Project LITT (Literacy Instruction Through Technology), a federally funded research study of the effectiveness of hypermedia-based children's 
literature software for enhancing the reading skills of students with learning disabilities. 